\title{
AN UNUSUAL PRESENTATION OF LANGERHANS CELL HISTIOCYTOSIS: PERIANAL LESION
}

\author{
Ali KANIK ${ }^{1}$, Kayı ELAÇIK ${ }^{1}$, Şehriban YESILOGLU ${ }^{1}$, Meral TURKER ${ }^{2}$, Mehmet HELVACI ${ }^{1}$, \\ Erdener OZER ${ }^{3}$
}

\begin{abstract}
${ }^{1}$ Department of Paediatrics, Tepecik Training and Research Hospital, Izmir, Turkey,

${ }^{2}$ Department of Paediatrics Hematology and Oncology, Tepecik Training and Research Hospital, Izmir, Turkey, ${ }^{3}$ Department of Pathology, Dokuz Eylul University Faculty of Medicine, Izmir, Turkey
\end{abstract}

Corresponding author:

Ali Kanik

Department of Paediatrics

Tepecik Training and Research Hospital Izmir, Turkey

dralikanik@hotmail.com

Tel.: + 905056711700

Fax.: + 902324330756

Received: July 2, 2013

Accepted: October 25, 2013

Copyright (C) 2014 by University Clinical Hospital Tuzla. E-mail for permission to publish: paediatricstoday@ukctuzla.ba
Objective - Langerhans cell histiocytosis is a rare disease characterized by monoclonal proliferation and infiltration of organs by large mononuclear cells. Here we report a case of Langerhans cell histiocytosis with non-classic perianal presentation and diabetes insipidus. Case report - A 10-year-old male patient diagnosed with central diabetes insipidus was referred to us with the complaints of abdominal pain, bloody stool, and an irregular ulceration on the bilateral perianal region. With the suspicion of inflammatory bowel disease the patient underwent colonoscopy and the result was normal. Due to the prior diagnosis of central diabetes insipidus the lesion was thought to be histiocytosis. A biopsy was performed and histological findings were consistent with Langerhans cell histiocytosis. Conclusion - Perianal involvement is an unusual presentation for Langerhans cell histiocytosis. In the case of suspicion of nonspecific ulceration of this area, the precise diagnosis should be made by histological means.

Key words: Langerhans cell histiocytosis - Perianal involvement Diabetes insipidus.

\section{Introduction}

Langerhans cell histiocytosis (LCH) is an uncommon clinically heterogeneous disorder, characterized by the proliferation and accumulation of Langerhans cells, with local infiltration of tissues and organ destruction (1). The annual incidence is 4 per million. The peak incidence of $\mathrm{LCH}$ is between the ages of 1 and 4 . Bone involvement is the most common manifestation of $\mathrm{LCH}$ and has been observed in $80-100 \%$ of cases. The other organs that commonly involved in LCH are: the skin (50\%), lymph nodes, bone marrow, lungs, hypothalamic pituitary axis (15-20\%), spleen and liver (30\%). General symptoms, such as fever, weight loss and lethargy, are common (2-4).

The involvement of the hypothalamic pituitary axis in the central nervous system causing diabetes insipitus (DI) is usually part of the systemic disease. DI may occur before the other clinical findings of $\mathrm{LCH}$, but more often develops within five years (5).

Dermatological manifestations occur typically during the course of the disease. Lesions that look like seborrheic dermatitis are often observed on the head, as well as a 
diffuse papular rash, and petechial lesions may occur in the intertriginous areas, such as around the ears, armpit and pubic region. However, perianal ulcerative lesions have rarely been reported in the literature (6).

Here, we present a case of $\mathrm{LCH}$ with an unusual perianal lesion and DI.

\section{Case report}

A 10-year-old male patient who was diagnosed with central diabetes insipidus at another centre was referred to our clinic for the preliminary diagnosis of inflammatory bowel disease, due to complaints of abdominal pain, blood in stool, and a lesion around the anus which continued for 2 months. He did not use desmopressin treatment regularly.

His growth-development and vital signs were within normal limits. Physical examination revealed vegetative nummular lesions, which were symmetric, showing central irregular ulceration on the perianal area (Fig. 1).

Other system examinations were normal, with no organomegaly and lymphadenopathy observed. In the laboratory examination, hemoglobin was $11.8 \mathrm{~g} / \mathrm{dl}$, leukocyte count was $6670 / \mathrm{mm}^{3}$ and platelet count was $451000 /$ $\mathrm{mm}^{3}$. Serum glucose, electrolytes, renal and hepatic function tests were all normal. Erythrocyte sedimentation rate was $45 \mathrm{~mm} / \mathrm{h}, \mathrm{C}$ reactive protein was negative. Serum immunoglobulin levels were normal. P-ANCA and anti saccharomyces antibodies were negative. Fecal occult blood was negative. MRI of the posterior pituitary detected no high signal for central DI. Cranial X-ray was normal. The colonoscopy, performed due to the suspicion of inflammatory bowel disease, was normal.

A skin biopsy was performed because of the nonspecific findings of skin lesion. Histological examination showed a polymorphic infiltrate with a major composition of lymphocytes, plasma cells, eosinophils, and among them there were histiocytes. Immunostaining was positive for S-100 and CD$1 \mathrm{a}$ and negative for CD-68. Morphological findings were consistent with the diagnosis of LCH (Fig. 2a, 2b).

After the diagnosis of $\mathrm{LCH}$, in the second week of the follow-up period a systemic evaluation for another involvement was carried out. A slight swelling in the jaw and gum hypertrophy were observed. Bone scintigraphy showed an expanding lesion of the left mandibular ramus. The patient was evaluated as stage $1 \mathrm{LCH}$ with these findings. Surgical intervention was not performed for the perianal lesion. His treatment was planned with systemic steroids and vinblastine. Local corticosteroid was administered to the perianal lesion for two weeks. However, no significant

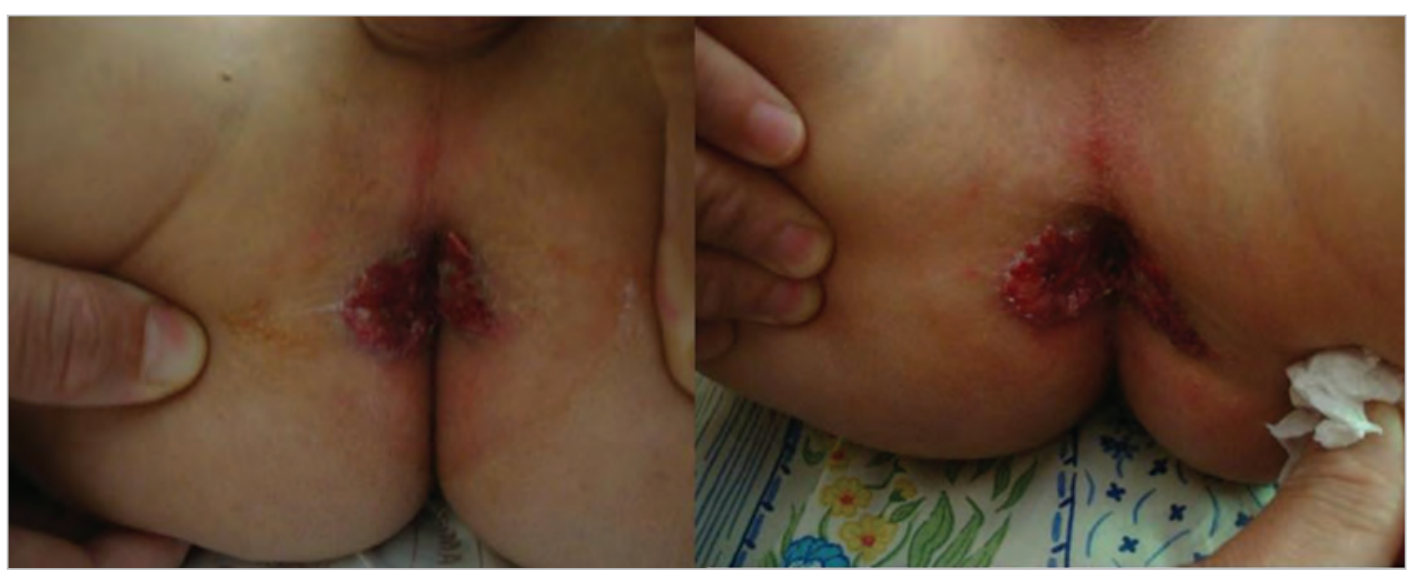

Fig. 1 The ulcerative lesion on the perianal area. 


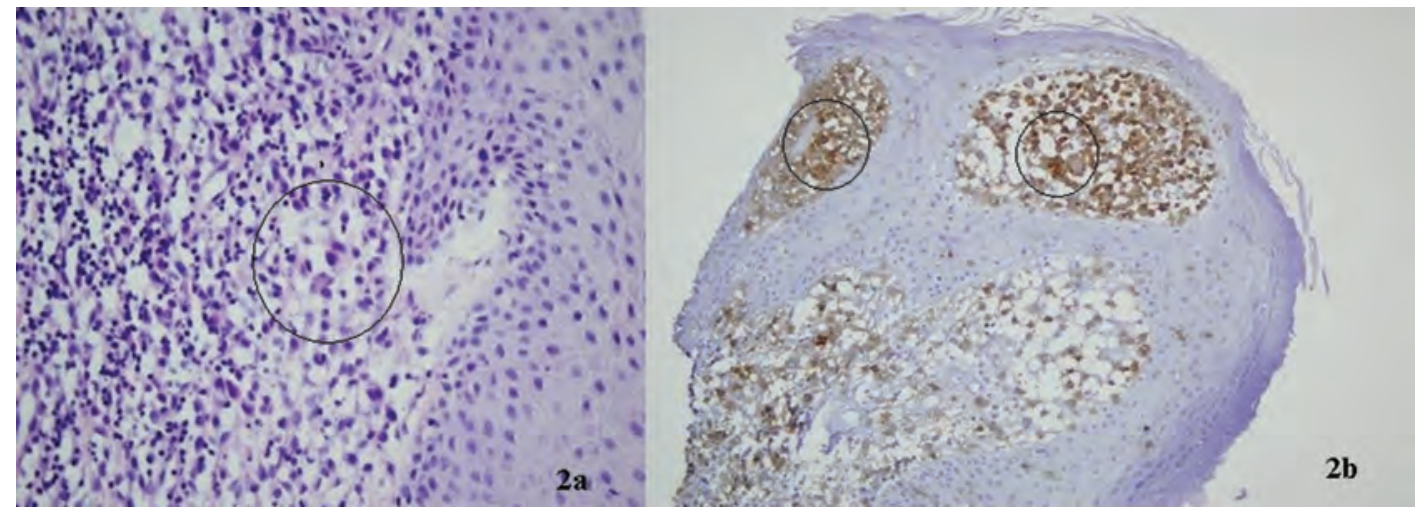

Fig. 2a Langerhans cells observed in polymorphic infiltrate in the dermis contained abundant cytoplasm and nuclei similar to coffee beans, HEx400; Fig. $\mathbf{2 b}$ Langerhans cells were stained diffuse positive with CD1a antibody in a immunohistochemical stain, $x 200$.

response was observed in this period and local therapy was stopped. With chemotherapy the lesion completely recovered in a three month period. During a one year period, triweekly administration of chemotherapy was continued and in the 2-year follow-up period no recurrence was observed.

\section{Discussion}

$\mathrm{LCH}$ is a rare proliferative disorder of the Langerhans cells. It occurs mostly in children and young adults. LCH encompasses a spectrum of disorders, with clinical presentations ranging from localized bone disease to severe multi-systemic involvement. The etiology and pathology of LCH remain unknown $(1,8)$.

$\mathrm{LCH}$ affects the skin in $40 \%$ of cases. The eruption may be extensive, involving the scalp, face, trunk, buttocks, and the intertriginous areas. Lesions consist of closely set petechiae and yellow-brown papules, topped with scale and crust. The papules may coalesce to form an erythematous, weeping or crusted eruption mimicking seborrheic dermatitis. Intertriginous lesions are often exudative, and secondary infection and ulceration may occur. The most common areas that lesions are seen in LCH are axilla, the groin and behind the ear, whereas the perianal region is rarely involved $(3,6)$. Our case was interesting because of the non-classic presentation of the lesion around the anus. Sabri et al. (8) reported a case with perianal lesions, gingival hyperplasia and systemic symptoms, Oguzkurt et al. (9) a case with diabetes insipidus and perianal lesions, without systemic symptoms, Kader et al. (6) a case with a perianal mass and multiple lytic skull lesions, and Shahidi-Dadras et al. (10) an adult perianal lesion case without systemic symptoms.

Complaints of abdominal pain and bloody stool led to difficulties in the diagnosis, which was only reached once the skin biopsy was performed and analyzed. In the follow-up, mandibular involvement was observed in our case so the patient was evaluated in the multi-system low-risk group. Chemotherapeutic agents are indicated for multi-system disease. Trials have shown combinations of vinblastine, etoposide and prednisolone for a period of six weeks to be effective, followed by mercaptopurine, vinblastine and prednisolone for one year (11). Steroids and vinblastine treatment were administered for one year period in our case. Prognosis is variable depending on the type of disease encountered. Unifocal LCH generally has an excellent prognosis, whereas the multifocal disease has a much poorer prognosis. Relapse 
is not uncommon and can occur up to 10 years after the disappearance of the original disease (11). No recurrence was observed in a 2-year follow-up period in our case. Conclusion: LCH should be kept in mind in the differential diagnosis of the perianal region. Therefore, biopsy and histological evaluation of lesions in this area should be carried out.

Authors' contributions: Conception and design: AK, $\mathrm{KE}$; Acquisition, analysis and interpretation of data: AK, KE, ŞY, MT, EÖ; Drafting the manuscript: MH, MT; Revising it critically for important intellectual content: MH, ŞY, EÖ.

Conflict of interest: The authors declare that they have no conflict of interest.

\section{References}

1. Willman CL, Busque L, Griffith BB, Favara BE, McClain KL, Duncan MH, et al. Langerhans'-cell histiocytosis (histiocytosis X)--a clonal proliferative disease. N Engl J Med. 1994;331(3):154-60.

2. Nicholson HS, Egeler RM, Nesbit ME. The epidemiology of Langerhans cell histiocytosis. Hematol Oncol Clin North Am. 1998;12(2):379-84.

3. Kilpatrick SE, Wenger DE, Gilchrist GS, Shives TC, Wollan PC, Unni KK. Langerhans' cell histiocytosis (histiocytosis $\mathrm{X}$ ) of bone. A clinicopathologic analysis of 263 pediatric and adult cases. Cancer. 1995;76(12):2471-84.
4. Liu YH, Fan XH, Fang K. Langerhans' cell histiocytosis with multisystem involvement in an adult. Clin Exp Dermatol. 2007;32(6):765-8.

5. Maghnie M, Cosi G, Genovese E, Manca-Bitti ML, Cohen A, Zecca S, et al. Central diabetes insipitus in children and young adults. New Engl J Med. 2000;343(14):998-1007.

6. Kader HA, Ruchelli E, Maller ES. Langerhans' cell histiocytosis with stool retention caused by a perianal mass. J Pediatr Gastroenterol Nutr. 1998;26(2):226-8.

7. Hanapiah F, Yaacob H, Ghani KS, Hussain AS. Histiocytosis X: Evidence for a genetic etiology. J Nihon Univ Sch Dent. 1993;35(3):171-4.

8. Sabri M, Davie J, Orlando S, Di Lorenzo C, Ranganathan S. Gastrointestinal presentation of Langerhans cell histiocytosis in a child with perianal skin tags: a case report. J Pediatr Gastroenterol Nutr. 2004;39(5):564-6.

9. Oguzkurt P, Sarialioglu F, Ezer SS, Ince E, Kayaselcuk F, Hicsonmez A. An uncommon presenting sign of Langerhans cell histiocytosis: focal perianal lesions without systemic involvement. J Pediatr Hematol Oncol. 2008;30(12):915-6.

10. Shadidi-Dadras M, Saeedi M, Shakoei S, Ayatollahi A. Langerhans cell histiocytosis: An uncommon presentation, successfully treated by thalidomide. Indian J Dermatol Venereol Leprol. 2011;77(5):587-90.

11. Foster A, Epanoimeritakis M, Moorehead J. Langerhans cell histiocytosis of the perianal region. Ulster Med J. 2003;7(1):50-1. 